\title{
Usporedba priroda i kakvoće plodova jabuke u integriranom i organskom proizvodnom sustavu
}

\author{
Comparison of apple yield and quality in integrated and organic \\ production system
}

\author{
Tea Presečki, M. Dropuljić, Irena Siladi
}

\section{SAŽETAK}

Organsko-biološka (ekološka) proizvodnja sve je zastupljenija u poljoprivredi svijeta tako i Hrvatske. Njome se želi postići održivost sustava bez uporabe sintetičkih gnojiva, pesticida, regulatora rasta i genetski modificiranih biljaka. Organska proizvodnja voća u svijetu prostire se na 12,6 milijuna hektara, od čega se jabuka uzgaja na 82983 hektara. U Europi su najznačajniji proizvođači Italija, Njemačka, Austrija, Nizozemska, Belgija i Francuska. U Republici Hrvatskoj organsko-biološka proizvodnja voća zauzima 8962 hektara, od čega na proizvodnju jabuka otpada 470 hektara.

Prema dosadašnjim istraživanjima, prirodi u organskim proizvodnim sustavima manji su od onih u integriranim proizvodnjama, međutim cijena proizvoda je veća pa se time taj nedostatak može nadomjestiti. Hrana iz organske proizvodnje ime više nutricionistički poželjnih spojeva (vitamini, antioksidansi), a manje nepoželjnih spojeva kao što su teški metali, mikotoksini i ostatci pesticida. Osim toga, jabuke iz organske proizvodnje imaju veću tvrdoću i bolji okus.

Ključne riječi: jabuka, prirod, kakvoća ploda, organska proizvodnja, integrirana proizvodnja

\begin{abstract}
Organic production is an increasingly popular term in agriculture around the world as is in Croatia. Organic farming is an agricultural system which seeks to achieve sustainability without the use of synthetic fertilisers and pesticides, growth regulators or genetically modified organisms. Organic fruit production spreads to 12,6 million hectares worldwide, while apple is produced on 82983 hectares. The largest producing countries in Europe are Italy, Germany, Austria, the Netherlands, Belgium and France. In Croatia organic fruit is produced on 8962 hectares, of which 470 hectares are for apple production.

In fruit production, as in other agricultural branches, the main goals are achieving desired yields and fruit quality. According to previous research, yields in organic
\end{abstract}


production systems are lower in comparison to those in integrated production. However, the price of organic produce is higher, which can compensate for aforementioned shortcomings. Furthermore, there is evidence of organically produced food containing more nutritionally desirable compounds, such as vitamins and antioxidants, while containing lower levels of heavy metals, mycotoxins and pesticide residue. Additionally, organically produced apples are found to have a higher level of hardness and a more appetizing taste, which are important factors in production.

Key words: apple, yield, fruit quality, organic production, integrated production

\section{UVOD}

Organsko-biološka (ekološka) proizvodnja sve je zastupljenija u svijetu pa tako i u Hrvatskoj. Voćari se sve više okreću ovom načinu uzgoja, ne samo zbog povećane potražnje, nego i potrebe za održivošću kako bi se očuvao ekosustav. Poljoprivredni sustavi dijele se na konvencionalni, integrirani i organski. Pod pojmom konvencionalne (industrijske) poljoprivrede smatra se poljoprivreda koja uključuje stvaranje visokorodnih kultivara i hibrida, suvremenu i intenzivnu agrotehniku, primjenu pesticida, herbicida i mineralnih gnojiva. Cilj konvencionalne proizvodnje je intenzivirati nasade, kako bi postali što produktivniji i riješili problem potrebe za hranom, što je dovelo i do pojave problema s plodnošću tla, smanjenja biološke raznolikosti, te zdravlja cijelog eko-sustava. Kao odgovor na nedostatke postojećeg sustava razvijen je integrirani pristup poljoprivrednoj proizvodnji koji se temelji na racionaliziranju korištenih sredstava i smanjenja negativnog učinka na eko-sustav. Prema pravilniku Republike Hrvatske iz 2012. godine (NN 137/2012) integrirana proizvodnja podrazumijeva uravnoteženu primjenu agrotehničkih mjera uz uvažavanje ekonomskih, ekoloških i toksikoloških čimbenika pri čemu se kod jednakog ekonomskog učinka prednost daje ekološki i toksikološki prihvatljivim mjerama. Integrirana proizvodnja prihvaćena je u Europi, kao i u svim razvijenijim zemljama svijeta kao bolji oblik konvencionalne proizvodnje. Pokret organske proizvodnje počeo je 1940-ih godina prošlog stoljeća dijelom zbog uvjerenja da je hrana koja se uzgaja upotrebom tradicionalnih metoda bez kemijskih sredstava zdravija (Worthington, 1998.). Organska proizvodnja oblik je poljoprivrede koji isključuje uporabu sintetičkih gnojiva i pesticida, regulatora rasta biljaka i genetski modificiranih biljaka (Roussos i sur., 2009.). Ključni ciljevi organske proizvodnje su: dugoročno povećavanje i održavanje plodnosti tla, opskrba biljaka potrebnim hranjivim tvarima putem prirodnih ili organskih gnojiva, očuvanje biološke raznolikosti, kontrola korova, štetnika 
i bolesti, očuvanje prirodnih grabežljivaca, zaštita prirodnih resursa od zagađenja i unapređenje zdravlja i produktivnosti uzajamno zavisnih zajednica života tla, biljaka, životinja i ljudi.

Organskom poljoprivredom želi se postići održivost sustava, međutim organsko ne znači i održivo. Da bi voćnjak bio održiv mora dati adekvatan prirod te samim time biti profitabilan, pridonositi očuvanju okoliša i prirodnih resursa, njime se mora upravljati na društveno odgovoran način.

Postoji dosta oprečnih rezultata o organskim sustavima proizvodnje. Dugo se tvrdilo da su manje efikasni, da predstavljaju veće zdravstvene rizike i da su prirodi manji od onih u integriranom sustavu (McArtney i Walker, 2004.). Glover i sur. (2000.) pokazali su da su prirod, profitabilnost i energetska učinkovitost organskih voćnjaka bolji nego $u$ integriranim sustavima proizvodnje u Washingtonu (SAD). Mnogi znanstvenici uspoređivali su kakvoću plodova uzgojenih u integriranim i organskim nasadima. Neki autori nisu pokazali značajne razlike između plodova jabuka iz organskih i integriranih voćnjaka, s obzirom na kakvoću ploda u berbi (Jönsson, 2007., Róth i sur., 2007.) ili nakon skladištenja (Róth i sur., 2007.). Drugi autori navode da je kakvoća jabuka iz organske proizvodnje bolja od onih iz integrirane (Reganold i sur., 2001; Peck i sur., 2006.). Bez obzira na podvojene rezultate, postoji dosta rezultata koji pokazuju da voće iz organske proizvodnje sadrži niže razine ostataka pesticida, nitratnog dušika, veću gustoću i bolji okus.

U većini zemalja organska proizvodnja jabuka i dalje je prilično ograničena, uglavnom zbog nedovoljno učinkovite kontrole štetnika i bolesti s organskim sredstvima za zaštitu bilja (Jönsson, 2007.) i nedostatka dovoljno efikasne strategije i tehnologije prorjeđivanja (McArtney i Walker, 2004.). Međutim, uz odgovarajuću tehnologiju, smatra se da integrirana i organska proizvodnja mogu pružiti konstantnu kakvoću plodova jabuka te omogućiti uzgajivačima siguran plasman na tržište.

Ekološka poljoprivreda razvijala se tijekom 20. stoljeća paralelno u nekoliko europskih zemalja (Švicarska, Njemačka, Austrija, Velika Britanija, Francuska) i u SAD-u. U svijetu su danas međunarodno prihvaćeni sustavi propisa i kontrole na temelju IFOAM-a (International Federation of Organic Agriculture Movements) standarda (od 1980. godine), te smjernicama Codexa Alimentarius-a (Lodeta i sur., 2011.). Europska unija je zakonski regulirala ekološku poljoprivredu donošenjem propisa o ekološkoj poljoprivredi i proizvodnji hrane 1991. godine (Uredba EU br. 2092/91). U Hrvatskoj je ekološka poljoprivreda zakonski regulirana 2001. godine prvim Zakonom o ekološkoj proizvodnji poljoprivrednih i prehrambenih proizvoda (NN br. 12/01) koji je bio u skladu s regulativama EU i IFOAM-a. Danas je on reguliran 
Zakonom o poljoprivredi (NN 30/15). Uredba Vijeća EZ-a br. 2018/848 objašnjava ekonomsku i ekološku važnost kao i značenje ekološke poljoprivrede za tržište Europske unije te daje smjernice pravnog okvira proizvodnje, prerade, distribucije i uvoza ekoloških poljoprivrednih i prehrambenih proizvoda.

Prema statističkim podacima ('The World of Organic Agriculture', 2018.), organska proizvodnja voća umjerenih područja 2016. godine u svijetu odvijala se na 12,6 milijuna hektara. Zemlje svijeta $\mathrm{s}$ najvećom proizvodnjom $\mathrm{u}$ hektarima su Kina, Italija, Poljska, Turska, Francuska te SAD. Od voćnih vrsta najviše se uzgajaju jabuke na 82983 hektara, slijede marelice, trešnje, breskve i nektarine, kruške i šljive. Erschbamer je, (2018.) iznijela podatak o udjelu najznačajnijih proizvođača organske jabuke u Europi. Prema podacima (Graf 1) vodeća zemlja je Italija, s pokrajinama Južni Tirol i Trentino, gdje se proizvodi $41 \%$ europske organske jabuke, nakon nje s malim zaostatkom slijedi Njemačka sa $38 \%$ organske proizvodnje, zatim Austrija sa $14 \%$, Nizozemska sa $3 \%$, te Belgija i Francuska sa 2\% organske proizvodnje.

Prema podacima Državnog zavoda za statistiku (www.dzs.hr) iz 2017. godine u Republici Hrvatskoj voće se uzgaja na ukupno 73479 hektara, od čega su jabuke zasađene na 4.838 hektara, dok je ukupna površina organskih trajnih

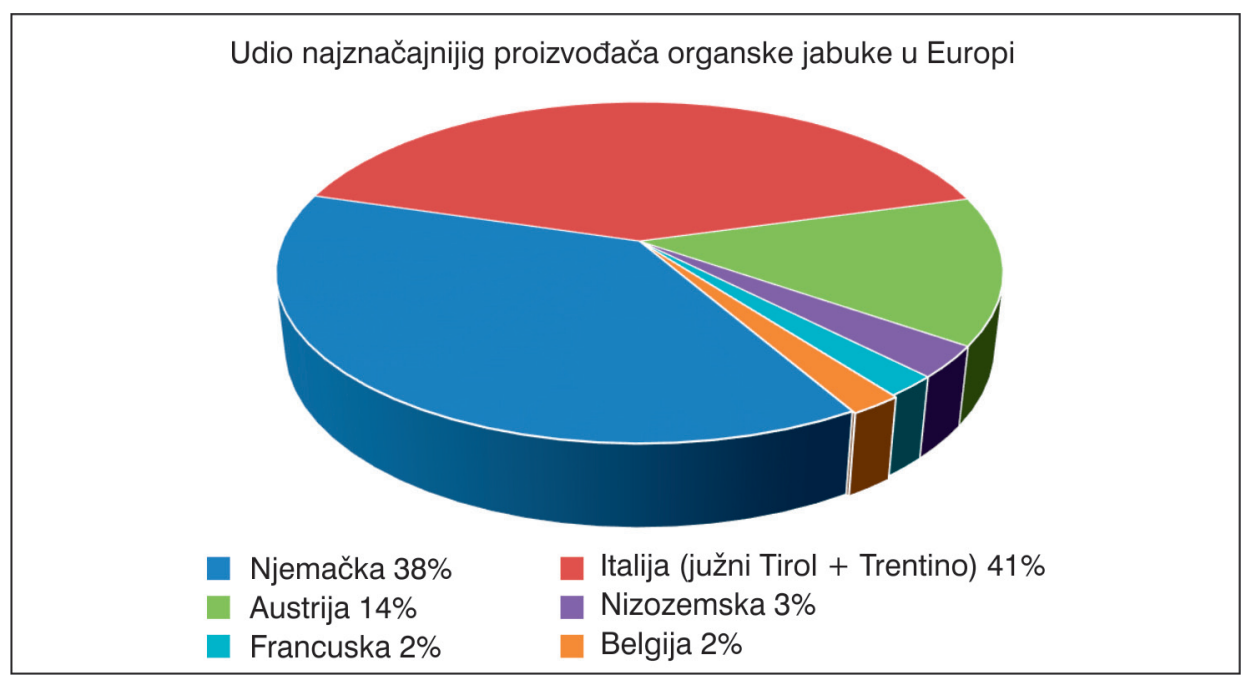

Graf 1. Udio najznačajnijih proizvođača organske jabuke u Europi (Izvor: Erschbamer, 2018.)

Figure 1 Distribution of the most important organic apple producers in Europe (Source: Erschbamer, 2018) 
nasada voća 8962 hektara, od čega se jabuka uzgaja na 470 hektara. Od 2013. do 2017. godine, površine pod organskom jabukom porasle su za 284 hektara.

\section{Analiza priroda}

Tehnološke spoznaje $u$ organskoj proizvodnji trenutno su slabije nego $u$ integriranoj, te mogu biti limitirajući faktor. Prirodi su manji u organskoj nego u integriranoj proizvodnji, te je i masa plodova uglavnom manja. Na Novom Zelandu prirodi su manji u organskoj proizvodnji (McArtney i Walker, 2004.), ali su cijene plodova veće, čime se nadoknađuje smanjeni prirod. Reganold i sur. (2001.) procjenjuju kako bi plodovi iz organskog uzgoja trebali imati 12$14 \%$ veću cijenu kako bi dostigli one iz integriranog uzgojnog sistema zbog većih troškova proizvodnje. Savjetodavna služba Južnog Tirola (Südtiroler Beratungsring für Obst und Weinbau, 2014.) daje preporuke za postizanje redovitih priroda i plodova dobre kakvoće na podlozi M9 kod organske i integrirane proizvodnje. Prema njihovim preporukama, ako želimo dobiti kvalitetan plod, prirod se mora smanjiti za 5-10 t/ha uz manju prosječnu masu plodova. Amarante i sur. (2008.) uspoređivali su sorte 'Royal Gala' i 'Fuji' u organskoj i integriranoj proizvodnji. Rezultati su pokazali kako nije bilo razlike u prirodu između ta dva načina proizvodnje kod 'Royal Gale', ali plodovi iz organske proizvodnje imali su manju prosječnu masu, dok su prirod i prosječna masa ploda kod sorte 'Fuji' bili manji u organskoj proizvodnji. Peck (2004.) je iznio podatak kako je prirod bio najniži u organskom sustavu u prvoj godini istraživanja ali najviši u drugoj godini. Druge godine je 50\% plodova težilo manje od $160 \mathrm{~g}$. Dobiveni podaci sugeriraju da je pokusni voćnjak ušao u naizmjeničnu rodnost, što pokazuje nedostatak tehnologije prihvatljive za organski sustav proizvodnje. Naizmjenična rodnost predstavlja značajan problem u svim sustavima proizvodnje, te je taj ciklus teško prekinuti bez adekvatne tehnologije. Zbog nedostatka učinkovitih organski certificiranih kemijskih sredstava za prorjeđivanje, naizmjenična rodnost navedena je kao jedna od značajnijih tehnoloških barijera za organsku proizvodnju jabuka (Glover i sur., 2000; Reganold i sur., 2001; Peck, 2004).

Usporedili smo podatke o prirodu Južnog Tirola u periodu od 2013. do 2017. godine u integriranom i organskom proizvodnom sustavu (Erschbamer, 2014 - 2018; Waldner, 2014 - 2018). Južni Tirol jedna je od najznačajnijih svjetskih regija kada je riječ o proizvodnji jabuke gdje se prirod kreće oko 60 tona po hektaru u integriranoj proizvodnji. Bez obzira što prosječni prirodi po hektaru ove regije znatno odskaču od prosjeka ostalih regija Europe, površine pod organskim tipom proizvodnje rastu iz godine u godinu. Proizvođači iz integriranog prelaze u organski oblik proizvodnje. Glavni razlozi za to su 
buđenje svijesti potrošača i postizanje viših cijena za proizvode iz organskog uzgoja.

U tablicama 1. i 2. navedeni su prirodi najznačajnijih sorata organske i integrirane proizvodnje u Južnom Tirolu u periodu od 2013. do 2017. godine. U integriranoj proizvodnji (tablica 1.), sorta 'Golden Delicious' je najzastupljenija, iza nje slijede 'Gala', 'Red Delicious', 'Braeburn', 'Fuji' i ostale. Za razliku od integriranih sustava, sorta 'Gala' najzastupljenija je u organskoj proizvodnji iako

Tablica 1. Prirodi jabuka sorata 'Golden Delicious', 'Gala', 'Red Delicious', 'Braeburn', 'Fuji', 'Granny Smith', 'Cripps Pink', 'Morgenduft', 'Jonagold - grupa', 'Winesap' i ostalih u Južnom Tirolu u integriranom tipu uzgoja, period 2013.-2017. (Waldner, 2014 - 2018).

Table 1. Yields of the apple varieties 'Golden Delicious', 'Gala', 'Red Delicious', 'Braeburn', 'Fuji', 'Granny Smith', 'Cripps Pink', 'Morgenduft', 'Jonagold - gorup', 'Winesap' and others in South Tyrol, in integrated type of cultivation, period of 2013. - 2017. (Waldner, 2014 - 2018).

\begin{tabular}{|c|c|c|c|c|c|}
\hline Sorta & $\begin{array}{c}\text { Procjena } \\
\text { priroda } 2013 \\
\text { (t) }\end{array}$ & $\begin{array}{c}\text { Procjena } \\
\text { priroda } \\
2014(t)\end{array}$ & $\begin{array}{c}\text { Procjena } \\
\text { priroda } 2015 \\
\text { (t) }\end{array}$ & $\begin{array}{c}\text { Procjena } \\
\text { priroda } 2016 \\
\text { (t) }\end{array}$ & $\begin{array}{c}\text { Procjena } \\
\text { priroda } 2017 \\
\text { (t) }\end{array}$ \\
\hline $\begin{array}{c}\text { Golden } \\
\text { Delicious }\end{array}$ & 454404 & 501501 & 459702 & 405665 & 353468 \\
\hline Gala & 165237 & 172197 & 180463 & 189421 & 167785 \\
\hline Red Delicious & 103596 & 139184 & 118650 & 114099 & 109716 \\
\hline Braeburn & 77950 & 82811 & 78943 & 79262 & 67866 \\
\hline Fuji & 65038 & 76507 & 77620 & 66211 & 66275 \\
\hline Granny Smith & 65486 & 82492 & 91456 & 81980 & 79590 \\
\hline Cripps Pink & 42067 & 49512 & 55015 & 64770 & 61476 \\
\hline Morgenduft & 14656 & 18828 & 12706 & 12536 & 11183 \\
\hline $\begin{array}{c}\begin{array}{c}\text { Jonagold - } \\
\text { grupa }\end{array} \\
\end{array}$ & 9956 & 12894 & 9206 & 8319 & 5000 \\
\hline Winesap & 7366 & 8499 & 8212 & 7482 & 5070 \\
\hline Ostale sorte & 39709 & 48921 & 57876 & 66972 & 62087 \\
\hline Procjena & 1045465 & 1193346 & 1149849 & 1096717 & 989516 \\
\hline $\begin{array}{c}\text { Stvarno } \\
\text { ubrano }\end{array}$ & 1103962 & 1199224 & 1127227 & 1063678 & 910767 \\
\hline Razlika (\%) & 5,60 & 0,49 & $-1,97$ & $-3,01$ & $-7,96$ \\
\hline
\end{tabular}

*godine u kojima je bilo značajnijih šteta od proljetnih mrazeva 
Tea Presečki i sur.: Usporedba priroda i kakvoće plodova jabuke $\mathrm{u}$ integriranom $\mathrm{i}$ organskom proizvodnom sustavu

Tablica 2. Prirodi jabuka sorata 'Gala', 'Golden Delicious', 'Braeburn', 'Pinova' + 'RoHo', 3615 / 'Evelina', 'Red Delicious', 'Cripps Pink / R.G. / 'Pink Lady', 'Topaz', 'Nicoter' / 'Kanzi', 'Fuji', 'Jonagold' - grupa, 'Granny Smith', Idared', SQ159 / 'Natyra', 'Pilot', 'Dalinbel' / 'Antares', 'Elstar', 'Coop 38' / 'GoldRush' i ostalih u Južnom Tirolu u organskom tipu uzgoja, periodu od 2013. do 2017. (Erschbamer, 2014 - 2018.).

Table 2. Yields of the apple variaties 'Gala', 'Golden Delicious', 'Braeburn', 'Pinova' + 'RoHo', 3615 / 'Evelina', 'Red Delicious', 'Cripps Pink '/ R.G. / 'Pink Lady', 'Topaz', 'Nicoter' / 'Kanzi', 'Fuji', 'Jonagold' - grupa, 'Granny Smith', Idared', SQ159 / 'Natyra', 'Pilot', 'Dalinbel' / 'Antares', 'Elstar', 'Coop 38' / 'GoldRush' and others in South Tyrol in organical type of cultivation, period 2013. - 2017. (Erschbamer, 2014 - 2018.).

\begin{tabular}{|c|c|c|c|c|c|}
\hline Sorta & $\begin{array}{c}\text { Prirod } 2013 \\
\text { (t) } \\
\end{array}$ & $\begin{array}{c}\text { Prirod } 2014 \\
\text { (t) }\end{array}$ & $\begin{array}{c}\text { Prirod } 2015 \\
\text { (t) }\end{array}$ & $\begin{array}{c}\text { Prirod } 2016 \\
(t) *\end{array}$ & $\begin{array}{c}\text { Prirod } 2017 \\
(\mathrm{t}) *\end{array}$ \\
\hline Gala & 10562 & 13431 & 14319 & 13412 & 12375 \\
\hline Golden Delicious & 11526 & 9952 & 9602 & 6153 & 5381 \\
\hline Braeburn & 4918 & 7183 & 6246 & 6962 & 4525 \\
\hline $\begin{array}{c}\text { Pinova + RoHo } \\
\text { 3615/Evelina }\end{array}$ & 2761 & 2978 & 3887 & 2827 & 2940 \\
\hline Red Delicious & 2745 & 2969 & 2675 & 2363 & 1772 \\
\hline C.Pink/R.G./Pink Lady & 1770 & 1810 & 1602 & 1756 & 1225 \\
\hline Topaz & 1248 & 1169 & 1323 & 974 & 858 \\
\hline Nicoter/Kanzi & 433 & 756 & 771 & 969 & 794 \\
\hline Fuji & 1716 & 1704 & 1805 & 1299 & 967 \\
\hline Jonagold - grupa & 1200 & 727 & 1223 & 410 & 633 \\
\hline Granny Smith & 542 & 703 & 756 & 567 & 522 \\
\hline Idared & 577 & 352 & 534 & 293 & 428 \\
\hline SQ159/Natyra & 1 & 1 & 1 & 1 & 34 \\
\hline Pilot & 59 & 49 & 73 & 70 & 50 \\
\hline Dalinbel/Antares & 1 & 33 & 38 & 32 & 28 \\
\hline Elstar & I & 26 & 27 & 21 & 14 \\
\hline Coop 38/GoldRush & 144 & 152 & 176 & 146 & 138 \\
\hline Ostale sorte & 1623 & 2359 & 1801 & 2378 & 1833 \\
\hline $\begin{array}{c}\text { Ukupno konzumne } \\
\text { jabuke }\end{array}$ & 41824 & 46353 & 46858 & 40632 & 34517 \\
\hline Industrijska jabuka & Nepoznato & Nepoznato & Nepoznato & 10387 & 10845 \\
\hline Ukupno & 41824 & 46353 & 46858 & 51019 & 45362 \\
\hline
\end{tabular}

*godine u kojima je bilo značajnijih šteta od proljetnih mrazeva 
spada u sorte koje su u periodu primarne zaraze osjetljive na krastavost ploda (Venturia inaequalis). Prema zastupljenosti, u organskoj proizvodnji nakon sorte 'Gala', najzastupljenija je sorta 'Golden Delicious', 'Braeburn', 'Pinova', 'Red Delicious' i 'Cripps Pink'. Iz podataka u tablici 2. možemo vidjeti kako je 2016. godine proizvedeno ukupno 51.019 tona organske jabuke od koje je $79,64 \%$ otpadalo na konzumnu, a 20,36\% na industrijsku jabuku. U sljedećoj godini proizvedeno je 45,362 tona sa sličnim udjelom klasa (76,08\% konzumne jabuke i $23,92 \%$ industrijske jabuke), s time da treba uzeti u obzir da su obje godine nasadi pretrpjeli štete od proljetnog mraza. Iz navedenih podataka možemo zaključiti kako se visokom tehnologijom i stručnošću može postići redovit prirod dobre kakvoće u organskoj proizvodnji kao i u integriranoj. Standardiziranje proizvodnje i konstantan rad na njezinom usavršavanju dovelo je do kontinuiranih i kvalitetnih priroda, što je glavni preduvjet za postizanje pozitivnog financijskog rezultata u globalnoj trgovini. Treba naglasiti kako je dobro praćenje proizvodnje dovelo do izrade procjene priroda koji odstupaju od stvarnih priroda za svega nekoliko postotaka, što se vidi u tablici 1. Tako dobra procjena omogućava tijelima i organizacijama koje se bave distribucijom i prodajom jabuke dobro planiranje prodaje i postizanje maksimalnih cijena koje su nužne za pozitivno poslovanje voćara regije.

\section{Analiza kakvoće plodova}

Kvalitetni plodovi koji zadovoljavaju tržište jedan su od najznačajnijih ciljeva koji želimo postići u proizvodnji. Rezultati su pokazali da organska proizvodnja hrane rezultira višim razinama nutricionistički poželjnih spojeva, uključujući vitamine, antioksidante i poli nezasićene masne kiseline te nižim razinama nutritivno nepoželjnih spojeva kao što su teški metali, mikotoksini, ostatci pesticida i glikoalkaloida (Niggli., 2009, citirao Gastoł., 2011).

Amarante i sur., (2008.), što su potvrdili Weibel i sur. (2004.), DeEll i Prange (1992.), i Peck i sur. (2006.), iznijeli su podatke kako su plodovi sorata 'Royal Gala' i 'Fuji' iz organske proizvodnje imali veću tvrdoću i sadržaj topljive suhe tvari. Plodovi su također bili veće gustoće što se može povezati sa manjom masom plodova, vjerojatno zbog manjih stanica te manjeg međustaničnog prostora (Amarante i sur., 2008.). Peck i sur. (2006.) istraživali su skladišnu sposobnost plodova sorte 'Galaxy Gala' iz organske i integrirane proizvodnje. Iznijeli su podatak kako su plodovi iz organskog uzgoja, nakon šestomjesečnog čuvanja u CA atmosferi imali $10 \%$ plodova ispod minimalne tržišno tražene tvrdoće, za razliku od onih iz integrirane $(36 \%)$ proizvodnje. Taj podatak mogao bi imati veliko ekonomsko značenje za proizvođače s obzirom da je to jedno od najznačajnijih svojstava kakvoće jabuke, te jedan od glavnih problema 
u proizvodnji. Organski uzgojena 'Royal Gala' imala je manji sadržaj ukupnih kiselina u istraživanju Amarantea i sur. (2008), dok su Peck i sur. (2006.) kod sorte 'Galaxy Gala' dobili skoro podjednake rezultate u oba sustava uzgoja. Nakon što su tjedan dana plodovi odstajali na sobnoj temperaturi (shelf-life), oni iz integrirane proizvodnje imali su više ukupnih kiselina. Omjer šećera i kiselina $u$ plodu $u$ vrijeme berbe nije pokazao značajne razlike između sustava uzgoja (Peck, 2004.).

Weibel i sur. (2004.) objavili su kako organski uzgojene jabuke sadrže više polifenola nego one uzgojene u sklopu integriranog sustava uzgoja. Peck i sur. (2006) primijetili su u svom istraživanju 5-12\% veću antioksidativnu aktivnost u plodovima iz organskog uzgoja nego kod integriranog uzgoja jabuka. Smatraju da dobiveni rezultati nisu povezani s abiotskim ni biotskim stresovima koji se povezuju s većom proizvodnjom antioksidansa $u$ plodu. Dobivene rezultate povezali su sa korištenjem glifosata, kojeg su koristili u integriranom uzgoju a ne u organskom. Glifosat inhibira enzim 5-enolpiruvilšikimat-3-fosfat sintazu (EPSPS) u biosintetskom putu flavonoida koji je povezan sa boljom antioksidativnom aktivnošću plodova.

Plodovi organski uzgojenih jabuka također su jače žućkaste pozadinske boje te većeg postotka crvenog obojenja. Bez obzira na razlike u svojstvima ploda, prema DeElliju i Prangeu (1992.) i Roth i sur. (2007.) senzoričari nisu pronašli značajne razlike u vidu okusa, arome i teksture, dok je Peck (2004.) senzornim analizama primijetio bolju teksturu i tvrdoću plodova iz organskog uzgoja. Također je iznio podatak gdje su potrošači uglavnom smatrali prihvatljivijom jabuku iz organskog nego iz integriranog uzgojnog sustava, pogotovo nakon što su degustirali plodove nakon čuvanja. Reganold i sur. (2001.) iznijeli su podatak kako plodovi iz organskih sustava proizvodnje imaju više šećera i manje kiselina nakon berbe i nakon šest mjeseci skladištenja od onih iz integriranog uzgojnog sustava.

Bolesti predstavljaju važan problem u organskom uzgoju, ponajviše zbog ograničavajućeg izbora sredstva za zaštitu. Istraživanjima su pronašli više plodova 'Fuji-a' sa pljesnivom jezgrom, što bi moglo ukazati na veći sadržaj patogena, i manju opskrbu hranjivima u organskom voćnjaku (Peck i sur., 2006). Jönsson, (2007.) navodi podatak o povećanoj smeđoj truleži, te većem propadanju plodova $\mathrm{u}$ organskoj nego $\mathrm{u}$ integriranoj proizvodnji. Plodovi sorte 'Fuji' imali su manju staklavost ploda, što je jedan od glavnih nedostataka te sorte, a povezan je $\mathrm{s}$ većom unutarnjom koncentracijom etilena, osobito $\mathrm{u}$ vrijeme kasnije berbe. Amarante i sur. (2008.) iznijeli su podatak kako plodovi sorte 'Galaxy Gala' i 'Fuji' uzgojeni u organskom voćnjaku imaju značajno veću hrđavost ploda, što može biti posljedica fitotoksičnog učinka sumpornog vapna 
i bordoške juhe koji se koriste za zaštitu od bolesti. U Nizozemskoj, tretiranje voćnjaka sumpornim vapnom povećalo je hrđavost ploda te smanjilo udio prve klase plodova (Holb i sur., 2003.). Na Novom Zelandu zabilježen je značajan porast odbačenog voća kao posljedice povećane hrđavosti ploda nakon tretiranja voćnjaka bakrenim fungicidima (Palmer i sur. 2003.).

\section{ZAKLJUČAK}

Organski sustavi proizvodnje, za razliku od integriranih još uvijek imaju veća tehnološka ograničenja kada se radi o kontroli opterećenja plodovima, zaštiti od bolesti i štetočina i održavanju plodnosti tla.

Unatoč velikim prednostima i koristima organske proizvodnje kao što su proizvodnja zdrave hrane te očuvanje prirodnih resursa (vode, tla i biološke raznolikosti) postoje ograničenja koja limitiraju njezinu ekspanziju u budućnosti. Budućnost organske proizvodnje ovisi o odgovoru na pitanje možemo li takvom proizvodnjom prehraniti svjetsko stanovništvo odnosno možemo li tehnološki usavršiti organsku proizvodnju do te mjere da čuvajući prirodu proizvedemo dovoljne količine zdrave i jeftine hrane dostupne većini svjetske populacije.

Sve dok ne pronađemo odgovor na ova pitanja, organska proizvodnja predstavljat će ekonomsku odskočnicu državama u razvoju i privilegiju potrošačima ekonomski razvijenih zemalja.

\section{LITERATURA}

Amarante, C. V. T. D., Steffens, C. A., Mafra, Á. L., \& Albuquerque, J. A. (2008.): Yield and fruit quality of apple from conventional and organic production systems. Pesquisa agropecuária brasileira. 43(3): 333-340.

Batelja Lodeta, K., Gugić, J., \& Čmelik, Z. (2012.): Ekološka poljoprivreda u Europi i Hrvatskoj s osvrtom na stanje u voćarstvu. Pomologia Croatica: Glasilo Hrvatskog agronomskog društva. 17(3-4): 135-148.

DeEll, J. R., \& Prange, R. K. (1992.): Postharvest quality and sensory attributes of organically and conventionally grown apples. HortScience. 27(10): 10961099 . 
Gąstoł, M., Domagała-Świątkiewicz, I., \& Krośniak, M. (2011.): Organic versus conventional-a comparative study on quality and nutritional value of fruit and vegetable juices. Biological Agriculture \& Horticulture. 27(3-4): 310319.

Glover, J. D., Reganold, J. P., \& Andrews, P. K. (2000.): Systematic method for rating soil quality of conventional, organic, and integrated apple orchards in Washington State. Agriculture, ecosystems \& environment. 80(1-2): 29-45.

Holb, I. J., De Jong, P. F., \& Heijne, B. (2003.): Efficacy and phytotoxicity of lime sulphur in organic apple production. Annals of Applied Biology. 142(2): 225-233.

Jönsson, Å. (2007.). Organic apple production in Sweden: cultivation and cultivars (Doctoral dissertation, Department of Crop Science, Swedish University of Agricultural Sciences).

McArtney, S. J., \& Walker, J. T. S. (2004.): Current situation and future challenges facing the production and marketing of organic fruit in Oceania. Acta Horticulturae. 387-398.

Palmer, J. W., Davies, S. B., Shaw, P. W., \& Wünsche, J. N. (2003.): Growth and fruit quality of 'Braeburn'apple (Malus domestica) trees as influenced by fungicide programmes suitable for organic production. New Zealand Journal of Crop and Horticultural Science. 31(2): 169-177.

Peck, G. (2004.): Orchard productivity and apple fruit quality of organic, conventional, and integrated farm management systems. (Doctoral thesis)

Peck, G. M., Andrews, P. K., Reganold, J. P., \& Fellman, J. K. (2006.): Apple orchard productivity and fruit quality under organic, conventional, and integrated management. HortScience. 41(1): 99-107.

Reganold, J. P., Glover, J. D., Andrews, P. K., \& Hinman, H. R. (2001.): Sustainability of three apple production systems. Nature. 410(6831): 926.

Róth, E., Berna, A., Beullens, K., Yarramraju, S., Lammertyn, J., Schenk, A., \& Nicolai, B. (2007.): Postharvest quality of integrated and organically produced apple fruit. Postharvest Biology and Technology. 45(1): 11-19.

Roussos, P. A., \& Gasparatos, D. (2009.): Apple tree growth and overall fruit quality under organic and conventional orchard management. Scientia Horticulturae. 123(2): 247-252. 
Weibel, F. P., Treutter, D., Häseli, A., \& Graf, U. (2004.): Sensory and healthrelated fruit quality of organic apples. A comparative field study over three years using conventional and holistic methods to assess fruit quality. In Ecofruit-11th International Conference on Cultivation Technique and Phytopathological Problems in Organic Fruit-Growing: Proceedings to the Conference from 3rd February to 5th February 2004 at Weinsberg/Germany (pp. 185-195).

Worthington V. (1998.): Effect of Agricultural Methods on Nutritional Quality: A Comparison of Organic with Conventional Crops. Alternative Therapies in Health and Medicine. 4(1).

Internet stranice i stručni časopisi:

DRŽAVNI ZAVOD ZA STATISTIKU (2018.): Površina ekoloških trajnih nasada u hektarima, Republika Hrvatska - www.dzs.hr. Pristupljeno 15.10.2018.

MICHAELA ERSCHBAMER, (2014.): Europa erwartet bisher größte BioApfelernte. Obstbau Weinbau Fachmagazin des Südtiroler Beratungsringes. 51: 230-231.

MICHAELA ERSCHBAMER, (2015.): In der EU gibt se 2015 weniger BioÄpfel. Obstbau Weinbau Fachmagazin des Südtiroler Beratungsringes. 52: 226-227.

MICHAELA ERSCHBAMER, (2016). Etwas weniger Bio-Äpfel und -Birnen erwartet. Obstbau Weinbau Fachmagazin des Südtiroler Beratungsringes. 53: $14-16$.

MICHAELA ERSCHBAMER, (2017). Deutlich weniger Bio-Äpfel und Birnen. Obstbau Weinbau Fachmagazin des Südtiroler Beratungsringes. 54: 15-16.

MICHAELA ERSCHBAMER, (2018). 2018 deutlich mehr Bio-Äpfel und BioBirnen. Obstbau Weinbau Fachmagazin des Südtiroler Beratungsringes. 55: 14-15.

NARODNE NOVINE, Pravilnik o integriranoj proizvodnji poljoprivrednih proizvoda - https://narodne-novine.nn.hr/clanci/sluzbeni/2012_12_137 2906.html. Pristupljeno 21.11.2018.

SÜDTIROLER BERATUNGSRING FÜR OBST UND WEINBAU, (2014). Leitfaden Apfelanbau 2014. 
SÜDTIROLER BERATUNGSRING FÜR OBST UND WEINBAU, (2014). Leitfaden Bio Apfelanbau 2014.

TRENDS 2010. IFOAM, Bonn; FiBL, Frick; ITC, Genf. - www.organicworld.net. Pristupljeno 16.10.2018.

WALTHER WALDNER, (2014). Südtirol erwartet 2014 knapp 1,2 Mio. Tonen Äpfel. Obstbau Weinbau Fachmagazin des Südtiroler Beratungsringes. 51: 228-230.

WALTHER WALDNER, (2015). Gesunde Südtiroler Äpfel für 60 Milionen Ernteprognose 2015 überraschend hoch. Obstbau Weinbau Fachmagazin des Südtiroler Beratungsringes. 52: 223-225.

WALTHER WALDNER, (2016). Heuer gibt es weniger Südtiroler Äpfel. Obstbau Weinbau Fachmagazin des Südtiroler Beratungsringes. 53: 11-13.

WALTHER WALDNER, (2017). Voraussichtliche Apfelernte 2017 in Südtirol und Italien. Obstbau Weinbau Fachmagazin des Südtiroler Beratungsringes. 54: 13-14.

WALTHER WALDNER, (2018). Schätzung der Apfelernte 2018 in Südtirol und Italien. Obstbau Weinbau Fachmagazin des Südtiroler Beratungsringes. 55. 12-13.

\section{Adresa autora - Authors addresses:}

Tea Presečki, e- mail: tea.presecki@hcphs.hr, Marko Dropuljić, Irena Siladi,

Hrvatski centar za poljoprivredu, hranu i selo; Zavod za voćarstvo i povrćarstvo Gorice 68 b, 10000 Zagreb 
